\title{
Correlation among Morphological, Biochemical and Physiological Responses under Iron Toxic Conditions in Rice
}

\author{
M. Amaranatha Reddy*, Rose Mary Francies, P.S. Abida and P. Suresh Kumar
}

Department of Plant Breeding and Genetics, College of Horticulture, Kerala Agricultural University, Thrissur, Kerala 680 656, India

*Corresponding author

\section{A B S T R A C T}

\section{Keywords}

Correlation,

Iron toxic

conditions,

Rice

Article Info

Accepted:

04 December 2018

Available Online:

10 January 2019

\begin{abstract}
$\mathrm{F}_{2}$ Population obtained from $\mathrm{F}_{1}$ cross between Tulasi (Most tolerant genotype) and CUL8709 (Most susceptible genotype). $300 \mathrm{~F}_{2}$ plants and their parents were screened at 800 ppm of Fe. Phenotyping screening of $\mathrm{F}_{2}$ plants under iron toxic levels indicated that leaf bronzing is associated with growth reduction due to $\mathrm{Fe}^{2+}$ toxicity in this $\mathrm{F}_{2}$ population confirms the usefulness of leaf bronzing index as criterion for differentiating between genotypes susceptible and tolerance to iron toxicity. This typical symptom of Fe toxicity, showed a strong negative correlation with shoot length, root length, total number of roots, number of fresh roots, shoot weight and root weight. Iron reversibly adsorbed on root surface was positively correlated with iron content in the root and observed in plants with lower leaf bronzing symptoms indicated that physiological mechanisms like Fe exclusion from roots and root tissue tolerance at higher Fe content in roots are predominant in $\mathrm{Fe}$ toxicity tolerance.
\end{abstract}

\section{Introduction}

Iron toxicity in soil is reported to be a widespread problem to affect more than $50 \%$ of lowland rice in Sri Lanka, Vietnam, Malaysia, India (especially in Kerala, Orissa, West Bengal and Andaman Islands), Indonesia, Philippines, Brazil, Columbia and Madagascar (Shimizu et al., 2005). Iron toxicity prevalent in the rice growing tracts of the state, further compounds the problem of low rice production. Yield reduction may range from 10 to $90 \%$ depending on soil, variety and growth stage of the appearance of symptoms (Sahrawat, 2004). Iron toxicity is characterized by the appearance of small brown spots on the lower leaves starting from the tips. Later the whole leaf turns brown, purple, yellow or orange. Growth and tillering are depressed and the root system is coarse, scanty and dark brown.

Great inter-varietal differences in iron toxicity tolerance in rice have been reported (Mohanty and Panda, 1991). Therefore, exploiting the varietal tolerance to iron toxicity is accepted as the most cost-effective and practical means for increasing rice production under iron toxic soils (Shimizu, 2009).Iron toxicity tolerance is a complex character and is influenced by 
various other characters therefore it is essential to understand the association of other characters with Iron toxicity tolerance in addition to the information on genetic variability (Dufey et al., 2015). Hence, association analysis was undertaken to determine the direction of selection and number of characteristics to be considered in improving iron toxicity tolerance. Correlation coefficient analysis measures the mutual relationship between two plant characters and determines component characters in which selection for tolerance to iron toxicity. Whether the association of these characters due to their directly relation with leaf bronzing answered through regression analysis. Such information reveals the possibility of simultaneous improvement of various attributes and also helps in increasing the efficiency of selection of complex inherited traits like iron toxicity tolerance. Keeping this in view, the present investigation aimed at correlation of various characters and regression effects of independent components on leaf bronzing symptoms in $300 \mathrm{~F}_{2}$ plants.

\section{Materials and Methods}

The experimental material for the study comprised of thirty rice genotypes selected from the KAU rice germplasm maintained at Regional Agricultural Research Station (RARS), KAU, Pattambi. The 30 rice genotypes were subjected to further screening to confirm their tolerance or susceptibility to iron toxicity. One most tolerant genotype (Tulasi) and most susceptible genotype (CUL8709) selected and used for development of $\mathrm{F}_{2}$ population. $300 \mathrm{~F}_{2}$ plants and their parents were screened at $800 \mathrm{ppm}$ of $\mathrm{Fe}$ through hydroponics. In the present study, an attempt has been made to understand the influence of iron at toxic level (800ppm) on growth parameters viz., shoot length, root length, total number of roots, number of fresh roots, shoot weight, root weight and visual scoring for iron-toxicity symptoms of $\mathrm{F}_{2}$ plants. The amount of iron reversibly adsorbed on root surface, iron content in root and leaf were also assessed.

\section{Results and Discussion}

Results indicated that, high significant positive correlation (0.71) was observed between leaf bronzing score (visual scoring for iron-toxicity symptoms) and iron content in the leaf. Whereas, the correlation between leaf bronzing score and traits root length $(-0.66)$, shoot length (-0.76), total number of roots ($0.81)$, number of fresh roots $(-0.98)$, root weight (-0.72), shoot weight $(-0.83)$, iron reversibly adsorbed on root surface (-0.94) and iron content in the root $(-0.61)$ was high significant and negative. Data on correlation analysis and simple regression analysis of $F_{2}$ plants is presented in the table 1 .

As resistance cannot be measured directly, several parameters were chosen as indicators of the degree of plant sensitivity to Fe toxicity. Iron toxicity tolerance is a complex character and is influenced by various other characters therefore it is essential to understand the association of other characters with iron toxicity tolerance in addition to the information on genetic variability (Dufey et al., 2015). Hence, association analysis was undertaken to determine the direction of selection and number of characteristics to be considered in improving iron toxicity tolerance.

Among all parameters analyzed, the most indicative of the degree of plant sensitivity to Fe toxicity was the LBI (Tanaka et al., 1966). This typical symptom of Fe toxicity, showed a strong negative correlation with shoot length, root length, total number of roots, number of fresh roots, shoot weight and root weight. The results indicated that leaf bronzing is associated with growth reduction due to $\mathrm{Fe}^{2+}$ 
toxicity in this $\mathrm{F}_{2}$ population. Wu et al., (1997) had reported that the leaf bronzing index is significantly negatively correlated with stem dry weight, tiller number and root dry weight. Previous studies have demonstrated that $\mathrm{Fe}$ toxicity in rice is characterized by bronzing spots on the lower leaves together with the formation of a red plaque on the roots and decreased biomass production (Audebert, 2006; Becker and Asch, 2005; Dorlodot et al., 2005; Green and Etherington, 1977; Howeler, 1973 and Sahrawat, 2004).

A study by Dufey et al., (2015) and Wan et al., (2003a) revealed negative correlation between leaf bronzing index (LBI) with the shoot dry weight (SDW) and root dry weight (RDW) ( $\mathrm{r}=-0.41$ and -0.39 respectively). Findings of the present study was in confirmation with the results of Olaleye et al., (2001) who reported a negative correlation between shoot length and shoot weight with leaf bronzing index. Fageria et al., (2008) and Dada and Aminu (2013) had also found a negative correlation between leaf bronzing index and shoot length.

In the present study, highly significant positive correlation between leaf bronzing index and iron contentin leaf was observed. Similar findings were also reported by Asch et al., (2005) and Nyamangyoku and Bertin (2013). All the above correlations, confirms the usefulness of LBI as criterion for differentiating between genotypes susceptible and tolerance to iron toxicity. Several earlier workers (Dufey et al., 2012; Wu et al., 2014) had relied on LBI scoring to identify genotypes tolerant to Fe stress.

The expression of iron-toxicity symptom requires the excessive uptake of $\mathrm{Fe}^{2+}$ by roots and its acropetal translocation via xylem flow into the leaves. Inside the leaf, excess amounts of $\mathrm{Fe}^{2+}$ cause an elevated production of radicals, which can cause irreversible damage to cell structural components (Thompson and Legge, 1987) and lead to an accumulation of oxidized polyphenols (Yamauchi and Peng, 1995). At the cellular level, it is not only insolubility, Butiron's high reactivity that can cause severe damage. Reactions involving iron in high concentrations in the interior of the cell may be highly damaging to the plant. These reactions can produce reactive species of oxygen, specifically the hydroxyl radical $\left(\mathrm{OH}^{-}\right)$, through the Fenton Reaction. The same physical properties that allow iron to act as an efficient cofactor and to catalyze controlled redox reactions also allow it to act as a powerful toxin when not protected from susceptible biomolecules. Numerous intracellular reactions use molecular oxygen as an electron acceptor producing superoxides $\left(\mathrm{O}^{2-}\right)$ or hydrogen peroxide $\left(\mathrm{H}_{2} \mathrm{O}_{2}\right)$. These species are not harmful, but they contribute to the generation of reactive oxygen species, hydroxyl radical $\left(\mathrm{OH}^{-}\right)$. Its formation is catalyzed by iron through the Fenton Reaction (Hell and Stephan, 2003). The typical visual symptom associated with those processes is the "bronzing" of the rice leaves (Howeler, 1973). Leaf Bronzing Symptom (LBS) was demonstrated to be highly correlated with yield formation under Fe-toxic field conditions (Audebert and Fofana, 2009).

A few $\mathrm{F}_{2}$ plants (Plant no. 20, Plant no. 52, Plant no. 110, Plant no. 111, Plant no. 156, Plant no. 246, Plant no. 248, Plant no. 268, Plant no. 287, Plant no. 300, Plant no. 308, Plant no. 309, Plant no. 319, Plant no. 320 and Plant no. 354) showed negligible leaf bronzing symptoms even at higher level of Fe content in their leaves. This indicated that tissue tolerance mechanism at leaf was also observed to some extent. On the subcellular level, the vacuole constitutes an important compartment for tissue tolerance at leaf through the storage of excess $\mathrm{Fe}^{2+}$ ions (Moore et al., 2014). Another mechanism of leaf tissue tolerance 
could be the scavenging of ROS through the plant's antioxidant network, thus avoiding the formation of oxidative stress. However, plants do not possess effective scavengers of the hydroxyl radical, the product of the Fenton reaction (Apel and Hirt, 2004). Therefore, antioxidants would have to remove the precursors of the hydroxyl radical such as hydrogen peroxide, which is reduced to water by antioxidant enzymes such as catalases and peroxidases (Blokhina et al., 2003).

As in the present study, Dufey et al., (2015) had also identified a high and positive correlation of the leaf bronzing index (LBI) with the Fe concentration in the leaf $(r=0.58)$. Iron reversibly adsorbed on root surface and iron content in root characters were positively correlated with shoot length, root length, total number of roots, number of fresh roots, shoot weight and root weight. Ferritin is considered crucial for iron homeostasis. It is said to consist of a multimeric spherical protein called phytoferritin, which is able to store up to 4500 iron atoms inside its cavity in non-toxic form. A resistant variety may accumulate a larger amount of phytoferritin, which forms a complex that reduces iron toxicity (Rout and Sahoo, 2015). It has been reported that tolerant rice roots have $\mathrm{Fe}$ retaining, $\mathrm{Fe}$ oxidizing and $\mathrm{Fe}$ excluding powers that reduce the amount of Fe in shoot and leaf. According to Tadano (1975), these mechanisms invariably involved retention of Fe in the root preventing their transport to the shoot. Secondly ferrous ion is oxidized to the non active ferric oxide form.

Toxicity symptoms are usually correlated with iron deposition in the roots (Barbosa Filho et al., 1994; Vahl, 1991). Kuraev (1966) reported that the initial toxic effect of high iron inhibits root development, and this was more pronounced at higher iron concentrations (200 $\mathrm{mgL}^{-1}$ ), which may have been due to possible toxicity mechanisms such as the iron-induced production of superoxide $\left(\mathrm{O}^{2-}\right)$. Tanaka et al.,
(1966) reported that high iron concentrations may influence the growth and distribution of various wetland plant taxa. Epilobium hirsutum roots also have some capacity that is clearly inadequate in high iron environments.

Iron reversibly adsorbed on root surface was positively correlated with iron content in the root and observed in plants with lower leaf bronzing symptoms. It indicated that, physiological mechanisms like Fe exclusion from roots and root tissue tolerance at higher $\mathrm{Fe}$ content in roots are predominant in $\mathrm{Fe}$ toxicity tolerance. Snowden and Wheeler (1995) found evidence of a clear relationship between the iron tolerance of a species and the nature of the root precipitate. Becker and Asch (2005) identified exclusion of $\mathrm{Fe}$ at the root surface by oxidation of $\mathrm{Fe}^{2+}$ into insoluble $\mathrm{Fe}^{3+}$ which leads to the formation of a root plaque i.e. precipitation of $\mathrm{Fe}$ at the root surface. Root architectural traits favoring this process include the formation of an aerenchyma and a large number of lateral fine roots, which facilitate the diffusion of oxygen into the rhizosphere, thereby increasing the redox potential above the threshold for $\mathrm{Fe}$ oxidation ( $\mathrm{Wu}$ et al., 2014). Higher iron content in the root due to regulating mechanisms for the transport of iron from roots to aerial parts are involved in those plants that show iron tolerance (Curie and Briat, 2003).

Negative correlation of iron content in leaf with iron content in root was supported by Majerus et al., (2007). Iron content in leaf was negatively correlated with root length, shoot length, root weight, shoot weight, total number of roots, number of fresh roots and iron reversibly adsorbed on root. Similarly, Onaga et al., (2013a) observed a significant negative correlation of iron content in leaf with root weight, shoot weight and tiller number under iron toxic conditions. 
Table.1 Correlation coefficients among leaf bronzing score and growth traits influenced under iron toxic condition (800 ppm Fe)

\begin{tabular}{|c|c|c|c|c|c|c|c|c|c|c|c|}
\hline Character & $\begin{array}{c}\text { Leaf } \\
\text { bronzing } \\
\text { after } 6 \\
\text { weeks }\end{array}$ & $\begin{array}{c}\text { Root } \\
\text { length }\end{array}$ & $\begin{array}{l}\text { Shoot } \\
\text { length }\end{array}$ & $\begin{array}{l}\text { Total } \\
\text { number } \\
\text { of roots }\end{array}$ & $\begin{array}{l}\text { Number } \\
\text { of fresh } \\
\text { roots }\end{array}$ & $\begin{array}{c}\text { Root } \\
\text { weight }\end{array}$ & $\begin{array}{l}\text { Shoot } \\
\text { weight }\end{array}$ & $\begin{array}{c}\text { Iron } \\
\text { adsorbed } \\
\text { on root } \\
\text { surface }\end{array}$ & $\begin{array}{c}\text { Iron } \\
\text { content } \\
\text { in root }\end{array}$ & $\begin{array}{l}\text { Leaf } \\
\text { iron } \\
\text { content }\end{array}$ & $\begin{array}{l}\text { Regression } \\
\text { on Leaf } \\
\text { Bronzing }\end{array}$ \\
\hline Root length (cm) & $-0.66 * *$ & 1.00 & & & & & & & & & 0.002 \\
\hline Shoot length $(\mathrm{cm})$ & $-0.76 * *$ & $0.79 * *$ & 1.00 & & & & & & & & -0.010 \\
\hline Total number of roots & $-0.81 * *$ & $0.80 * *$ & $0.85 * *$ & 1.00 & & & & & & & $0.073^{* *}$ \\
\hline Number of fresh roots & $-0.98 * *$ & $0.68 * *$ & $0.78 * *$ & $0.84 * *$ & 1.00 & & & & & & $-0.282^{* *}$ \\
\hline Root weight (g) & $-0.72 * *$ & $0.71 * *$ & $0.75 * *$ & $0.78 * *$ & $0.74 * *$ & 1.00 & & & & & 0.035 \\
\hline Shoot weight (g) & $-0.83 * *$ & $0.70 * *$ & $0.82 * *$ & $0.82 * *$ & $0.84 * *$ & $0.85 * *$ & 1.00 & & & & $-0.063 *$ \\
\hline $\begin{array}{l}\text { Iron adsorbed on root surface } \\
\left(\mathrm{mg} \mathrm{l}^{-1}\right)\end{array}$ & $-0.94 * *$ & $0.68 * *$ & $0.78 * *$ & $0.83 * *$ & $0.96 * *$ & $0.75 * *$ & $0.83 * *$ & 1.00 & & & $-0.116^{* *}$ \\
\hline Iron content in root $\left(\mathrm{mg} \mathrm{kg}^{-1}\right)$ & $-0.61 * *$ & $0.40 * *$ & $0.54 * *$ & $0.53 * *$ & $0.64 * *$ & $0.41 * *$ & $0.52 * *$ & $0.67 * *$ & 1.00 & & 0.000 \\
\hline $\begin{array}{l}\text { Iron content in oldest leaf } \\
\left(\mathrm{mg} \mathrm{kg}^{-1}\right)\end{array}$ & $0.71 * *$ & $-0.55 * *$ & $-0.63 * *$ & $-0.69 * *$ & $-0.76 * *$ & $-0.57 * *$ & $-0.64 * *$ & $-0.79 * *$ & $-0.62 * *$ & 1.00 & $-0.001 * *$ \\
\hline
\end{tabular}

*significant at $5 \%$ level; **significant at $1 \%$ level 
Nyamangyoku and Bertin (2013) also observed highly significant negative correlation of leaf iron concentration with leaf dry weight. The yield reduction by Fe toxicity was associated with the growth inhibition, especially at the later stages of growth.

During this period, the Fe content of roots of tolerant lines increased more slowly than those of susceptible lines. Also, the Fe content in soil solution sampled from plots of tolerant lines was higher than in those of susceptible lines. These findings suggest that a $\mathrm{Fe}$ exclusion mechanism is operating in the roots of tolerant lines (Nozoe et al., 2008).

Traits like root length, shoot length, root weight, shoot weight, total number of roots, number of fresh roots, iron reversibly adsorbed on root and iron content in root were positively correlated each other. Similarly, Wang et al., (2013) observed positive correlation among shoot length, root length, root weight and shoot weight characters. Highly significant positive correlation between root weight and shoot weight characters was also observed by Wan et al., (2003a), Onaga et al., (2013a) and Dufey et al., (2015). Olaleye et al., (2001) observed positive correlation between shoot length and shoot weight and similar results were observed in the present study.

Regression analysis revealed that number of roots has effects that are more positive with leaf bronzing score. Total number of fresh roots has effects that are more positive with leaf bronzing score followed by iron adsorbed on root surface and shoot weight. Higher values of total number of fresh roots, iron adsorbed on root surface and shoot weight helps in development of tolerance to iron toxicity in rice. Root length, shoot length, root weight and iron content in root has no effects on leaf bronzing score.

\section{References}

Apel, K. and Hirt, H. 2004. Reactive oxygen species: metabolism, oxidative stress, and signal transduction. Annu. Rev. PlantBiol. 55: 373-399.

Asch, F., Becker, M., and Kpongor, D. S. 2005. A quick and efficient screen for tolerance to iron toxicity in lowland rice. J. Plant Nutr. Soil Sci. 168: 764773.

Audebert, A. 2006. Rice yield gap due to iron toxicity in West Africa. In: Audebert, A., Narteh, L. T., Paul, K., Millar, D., and Beks, B. (eds), Iron toxicity in ricebased systems in West Africa.WARDA (West Afr. Rice Dev. Assoc.), pp. 47-63.

Audebert, A. and Fofana, M. 2009. Rice yield gap due to iron toxicity in West Africa. J. Agron. Crop Sci. 195: 66-76.

BarbosaFilho, M. P., Dynia, J. F., and Fageria, N. K.1994. Zinc and iron in the rice crop (in portuguese). EMBRAPASPI, Brasilia. 71pp.

Becker, M. and Asch. F. 2005. Iron Toxicity Conditions and management concepts. J. Plant Nutr. Soil Sci. 168: 558-573.

Becker, M. and Asch. F. 2005. Iron Toxicity Conditions and management concepts. J. Plant Nutr. Soil Sci. 168: 558-573.

Blokhina, O., Virolainen, E., and Fagerstedt, K., V. 2003. Antioxidants, oxidative damage and oxygen deprivation stress: a review. Ann.Bot. 91: 179-194.

Curie, C. and Briat, J. F. 2003. Iron transport and signaling in plants. Аnnu. Rev. Plant Biol. 54: 183-206.

Dada, O. A. and Aminu, J. A. 2013. The performance of lowland rice (Oryza sativa L.) cultivars on iron toxic soil augmented with compost. J. Stress Physiol. Biochem. 9 (4): 207-218.

Dorlodot, S., Lutts, S., and Bertin, P. 2005. Effects of ferrous iron toxicity on the growth and mineral composition of interspecific rice. J. Plant Nutr. 28(1): 
118-120.

Dufey, I., Draye, X., Lutts, S., Lorieux, M., Martinez, C., and Bertin, P. 2015. Novel QTLs in an inter-specific backcross Oryza sativa $\mathrm{x}$ Oryzaglaberrima for resistance to iron toxicity in rice. Euphytica, 3: 609-625.

Dufey, I., Hiel, M. P., Hakizimana, P., Draye, X., Lutts, S., Kone, B., Drame, K. N., Konate, K. A., Sie, M., and Bertin, P. 2012. Multi-environment Quantitative Trait Loci mapping and consistency across environments of resistance mechanisms to ferrous iron toxicity in rice. Crop Sci. 52: 539-550.

Fagaria, N. K., Santos, N. A. B., Barbosa, M. P., and Quimanqes, C. M. 2008. Iron toxicity in lowland rice. J. Plant Nutr. 31(9): 1676-1699.

Green, M. S., Etherington, J. R.1977. Oxidation of ferrous iron by rice roots: A mechanism for waterlogging tolerance. J. Exp. Bot. 28: 678-690.

Hell, R. and Stephan, U. 2003. Iron uptake, trafficking and homeostasis in plants. Planta, 216: 541-551.

Howeler, R. H. 1973. Iron-induced ringing disease in relation to physicochemical changes in a flooded Oxisol. Soil Sci. Soc. american. Proc. 37: 898-903.

Howeler, R. H. 1973. Iron-induced ringing disease in relation to physicochemical changes in a flooded Oxisol. Soil Sci. Soc. american. Proc. 37: 898-903.

Kuraev, V. N. 1966. Effects of various concentrations of ferrous iron in culture solution on the growth and development of agricultural plants. Agrokhimia, 12:110-117.

Majerus, V., Bertin, P., and Lutts, S. 2007. Effects of iron toxicity on osmotic potential, osmolytes and polyamines concentrations in the African rice (Oryza glaberrima Steud.) Plant Sci. 173: 96-105.

Mohanty, S. K. and Panda, K. 1991. Varietal behaviour of rice towards $\mathrm{Fe}$ toxicity. Oryza 28: 513-515.

Moore, K. L., Chen, Y., Meene, A. M. L., Hughes, L., Liu, W., Geraki, T., Mosselmans, F., McGrath, S. P., Grovenor, C., and Zhao, F. J. 2014. Combined NanoSIMS and synchrotron $\mathrm{X}$-ray fluorescence reveal distinct cellular and subcellular distribution patterns of trace elements in rice tissues. New Phytol. 20:104-115.

Nozoe, T., Agbisit, R., Fukuta, Y., Rodriguez, R., and Yanagihara, S. 2008. Characteristics of iron tolerant rice lines developed at IRRI under field conditions. Japan Agric. Res. Q. 42 (3): 187-192.

Nyamangyoku, I. O. and Bertin, P. 2013. Mechanisms of resistance to ferrous iron toxicity in cutivated rices: Oryza sativa L., Oryza glaberrima Steud and Interspecific Hybrids. J. Plant Nutr. Soil Sci. 168: 764-773.

Olaleye, A. O., Tabi, F. O., Ogunkunle, A. O., Singh, B. N., and Sahrawat, K. L. 2001. Effect of Toxic Iron Concentrations on the Growth of Lowland Rice. J. Plant Nutri. 24(3): 441-457.

Onaga, G., Edemab, R., and Aseaa, G. 2013a. Tolerance of rice germplasm to iron toxicity stress, the relationship between tolerance, $\mathrm{Fe}^{2+}, \mathrm{P}$ and $\mathrm{K}$ content in the leaves and roots. Arch. Agron. Soil Sci. 59 (2): 213-229.

Rout, G. R., Sahoo, S., Das, A. B., and Das, S. R. 2014. Screening of Iron Toxicity In Rice Genotypes on the Basis of Morphological, Physiological and Biochemical Analysis. J. Exp. Biol. Agric. Sci. 2(6): 239-244.

Sahrawat, K. L. 2004. Iron toxicity in wetland rice and the role of other nutrients. $J$. Plant Nutr. 27: 1471-1504.

Sahrawat, K. L. 2004. Iron toxicity in wetland rice and the role of other nutrients. $J$. Plant Nutr. 27: 1471-1504. 
Shimizu, A. 2009. QTL analysis of genetic tolerance to iron toxicity in rice (Oryza sativa $\mathrm{L}$.) by quantification of bronzing score. J. New seeds 10(3): 171-179.

Shimizu, A., Guerta, C. Q., Gregorio, G. B., Kawasaki, S., and Ikehashi, H. 2005. QTLs for nutritional contents of rice seedlings (Oryza sativa L.) in solution cultures and its implication to tolerance to iron-toxicity. Plant Soil 275: 57-66.

Snowden, R. E. D. and Wheeler, B. D. 1995. Chemical changes in selected wetland plant species with increasing Fe supply, with specific reference to root precipitates and $\mathrm{Fe}$ tolerance. New Phytologist, 131: 503-520.

Tadano, T. 1975. Devices of rice roots to tolerated high iron concentration in growth media. Japan. Agr. Res. 9: 3439.

Tanaka, A., Loe, R., and Navasero, S. A. 1966. Some mechanism involved in the development of iron toxicity symptoms in the rice plant. Soil Sci. Plant Nutr.12: $158-164$.

Thompson, J. E. and Legge, R. L. 1987. The role of free radicals in senescence and wounding. New Phytologist 105: $317-$ 344.

Vahl, L. C. 1991. Iron toxicity in rice genotypes irrigated by flooding. Ph.D. Thesis. Federal University of Rio grande do Sul, Porto Alegre, 167p.

Wan, J. L., Zhai, H. Q., Wan J. M., and Ikehashi, H. 2003a. Detection and analysis of QTLs for ferrous iron toxicity tolerance in rice (Oryza sativa L.). Euphytica, 131: 201-206.

Wang, Y. P., Wu, Y. H., Liu, P., Zheng, G. H., Zhang, J. P., and Xu, G. D. 2013. Effects of potassium on organic acid metabolism of Fe-sensitive and $\mathrm{Fe}$ resistant rices (Oryza sativa L.). Asian J. crop sci. 7(6): 843-848.

Wu, L., Shhadi, M. Y., Gregorio, G., Matthus, E., Becker, M., and Frei, M. 2014. Genetic and physiological analysis of tolerance to acute iron toxicity in rice. Rice 7: 8-9.

Wu, L., Shhadi, M. Y., Gregorio, G., Matthus, E., Becker, M., and Frei, M. 2014. Genetic and physiological analysis of tolerance to acute iron toxicity in rice. Rice 7: 8-9.

Wu, P., Luo, A., Zhu, J., Yang, J., Huang, N., and Senadhira, D. 1997. Molecular markers linked to genes underlying seedling tolerance for ferrous iron toxicity. Plant Soil 196(2): 317-320.

Yamauchi, M. and Peng, X. X. 1995. Iron toxicity and stress-induced ethylene production in rice leaves. Plant and Soil 173: 21-28.

\section{How to cite this article:}

Amaranatha Reddy, M., Rose Mary Francies, P.S. Abida and Suresh Kumar, P. 2019. Correlation among Morphological, Biochemical and Physiological Responses under Iron Toxic Conditions in Rice. Int.J.Curr.Microbiol.App.Sci. 8(01): 37-44. doi: https://doi.org/10.20546/ijcmas.2019.801.005 